\title{
Triamcinolone Acetonide for the Treatment of Diabetic Macular Oedema
}

\author{
Valentina Sarao, Daniele Veritti and Paolo Lanzetta
}

Department of Ophthalmology, University of Udine

\begin{abstract}
Diabetic macular oedema is a major cause of severe visual loss whose pathogenesis appears to be complex and multifactorial. For many years laser photocoagulation has been the standard of care for the treatment of this condition. Emerging pharmacologic approaches are being evaluated through randomised controlled trials. Triamcinolone acetonide has been proposed as a promising option, due to its well-known anti-inflammatory, anti-permeability and anti-angiogenic properties. Intravitreal delivery allows bypassing of the blood-retinal barrier to achieve a more concentrated dose of steroid in the vitreal cavity for a prolonged time. Intravitreal triamcinolone acetonide is effective in reducing central macular thickness and improving visual acuity, even if the duration of action is often provisional and requires repeated injections. Drug-related and injection-related side effects have been reported; the most common are induced cataract and increased intraocular pressure. To extend the duration of steroid effects and to minimise the risk of complications, alternative routes of administration and extend-release implants are being investigated.
\end{abstract}

\section{Keywords}

Diabetic macula oedema, diabetic retinopathy, laser photocoagulation, intraocular pressure, triamcinolone acetonide

Disclosure: Daniele Veritti and Valentina Sarao have no conflicts of interest to declare. Paolo Lanzetta is consultant to Novartis Pharma AG, Allergan and Bayer AG. Received: 17 October 2011 Accepted: 18 November 2011 Citation: European Ophthalmic Review, 2012;6(1):28-33 DOI: 10.17925/EOR.2012.06.01.28 Correspondence: Paolo Lanzetta, Department of Ophthalmology, University of Udine, Piazzale S. Maria della Misericordia, 33100 Udine, Italy. E: paolo.lanzetta@uniud.it

Triamcinolone acetonide (TA) is a synthetic steroid of the glucocorticoid family with a fluorine in the ninth position. ${ }^{1}$ It is commercially available as an ester and represents one of the most commonly used steroid agents for the treatment of several retinal conditions. ${ }^{2}$

TA has an anti-inflammatory potency five times higher than hydrocortisone with a 10th of the sodium-retaining potency. It appears as a white- to cream-colored crystalline powder and it is practically insoluble in water and very soluble in alcohol. ${ }^{3}$ The decreased water solubility accounts for its prolonged duration of action. It has been observed that adequate concentrations of TA could provide therapeutic effects for approximately three months after $4 \mathrm{mg}$ intravitreal TA injection. ${ }^{4} \mathrm{~A}$ maximum effect duration of 140 days has been suggested. ${ }^{5,6}$

\section{Mechanism}

TA has been shown to inhibit the inflammatory response, thereby reducing oedema formation, leukocyte migration, capillary dilatation and fibroblast proliferation. Steroids are thought to act by the induction of proteins called lipocortins, in particular phospholipase A2. These proteins reduce leukocyte chemotaxis, control biosynthesis and inhibit the release of arachidonic acid from the phospholipid membrane, which is one of the most important common precursors of potent inflammatory cell mediators such as prostaglandins and leukotrienes. ${ }^{8}$ The anti-inflammatory, angiostatic and anti-permeability proprieties of corticosteroids seem also to be related to the regulation of gene expression components. This regulation influences the expression of vascular endothelial growth factor (VEGF), inhibits pro-inflammatory genes such as tumour necrosis factor-alpha (TNF- $\alpha$ ) and other inflammatory chemokines, and induces the expression of anti-inflammatory factors such as pigment epithelium-derived factor (PEDF). ${ }^{9-11}$ Some studies show that TA, at therapeutic concentrations, significantly inhibits the expression of TNF- $\alpha$, interleukin 1-beta (IL-1 $\beta$ ), thromboxane B2 (TXB2) and leukotriene B4 (LTB4), in a dose-dependent manner. ${ }^{12}$ Additionally, TA seems to reduce the expression of matrix metalloproteinases (MMPS) and to downregulate intercellular adhesion molecule 1 (ICAM-1) on choroidal endothelial cells. ${ }^{13}$

\section{Efficacy of Intravitreal Triamcinolone Acetonide}

Based on several studies, intravitreal administration of TA has provided promising results for the treatment of disorders associated with an abnormal endothelial cell proliferation and conditions complicated by intra-retinal and subretinal fluid accumulation. The anti-inflammatory, angiostatic and anti-permeability properties of TA have gained interest in chronic retinal diseases, such as diabetic macular oedema (DMO). ${ }^{14-18} \mathrm{DMO}$ is the leading cause of vision loss in the working-age population and it occurs as an increased accumulation of fluid within the intra-retinal layers of the macula as a result of retinal microvascular changes and disruption of the blood-retinal barrier. The rationale for using a steroidal drug for the treatment of oedematous and proliferative diseases is that abnormal proliferation of cells is often associated with and trigged by inflammation and intra-retinal accumulation of fluid is usually accompanied by a blood-retinal barrier dysfunction that can be restored with steroid therapy. ${ }^{19}$ Intravitreal TA has been widely studied in many randomised clinical trials on DMO demonstrating significant improvements both in morphological and functional outcomes. ${ }^{20-23}$ Focal and grid laser photocoagulation has been considered the 
standard of care for the treatment of DMO for many years. ${ }^{24,25}$ However, a substantial group of patients are unresponsive to laser therapy and fail to improve after photocoagulation. It has been reported that three years after initial grid treatment visual acuity improved in $14.5 \%$ of eyes, did not change in $60.9 \%$ and decreased in $24.6 \%$ of patients with DMO. ${ }^{26}$ Therefore, TA has been tested for the treatment of DMO, either naïve or diffuse and refractory to laser therapy. In most cases, TA has been administered intravitreally. However, other delivery routes have been tested, such as sub-Tenon, juxtascleral and sub-conjuntival administration. The current commercial preparations of TA include products that received dermatologic and orthopaedic indications and are considered off-label for the intraocular use, products registered as devices for assisting the visualisation of the vitreous during vitreoretinal procedures and products that are registered for intraocular use in uveitis and other ocular inflammatory conditions. Kenalog-40 (40 mg/ml, Bristol-Myers Squibb, NJ) is the most common intraocular steroid and has been widely used as intravitreal injections since 2004 for the treatment of several retinal diseases. This formulation is US Food and Drug Administration (FDA)-approved only for intramuscular and intra-articular use and is currently employed off-label for intraocular injections. Trivaris ${ }^{\mathrm{TM}}$ ( $80 \mathrm{mg} / \mathrm{ml}$, Allergan Inc., Irvine, CA) and Triesence ${ }^{\circledR}$ (40 mg/ml, Alcon Inc., Fort Worth, TX) are preservative-free brands of TA recently FDA approved for ophthalmic use in the treatment of sympathetic ophthalmia, temporal arteritis, uveitis and other ocular inflammatory diseases unresponsive to topical corticosteroids. Vitreal S (Sooft s.p.a., Fermo, Italy) is a medical device used in endocular surgery to stain the vitreous during vitrectomy and it is not registered as drug for intraocular use. There are some issues regarding the formulation of TA used for intraocular administration. A previous phase-contrast microscopy study showed a notable difference of crystal size depending upon the drug formulation. ${ }^{27}$ Very large and irregular crystals, with a significant heterogeneity in crystal size, were occasionally found in the off-label commercially available, benzyl-alcohol-preserved TA, whereas the crystals of a preservative-free in-label commercially available TA suspension appeared to be relatively uniform in size. These morphologic aspects may have a significant impact on the half-life of the drug both in vivo and in vitro. This hypothesis is based on the fact that smaller crystals have a superior surface-area-to-volume ratio, allowing them to be dissolved more rapidly. The formulations containing crystals that widely vary in size and, thus, including larger crystals may theoretically generate a wider time-drug concentration curve because of their slower dissolution rate..$^{27-29}$

A carefully designed prospective randomised trial conducted by the Diabetic Retinopathy Clinical Research Network (DRCR.net) investigated the efficacy and safety of $1 \mathrm{mg}$ and $4 \mathrm{mg}$ doses of preservative-free intravitreal TA in comparison with focal or grid laser photocoagulation. ${ }^{30}$ In the DRCR.net study, 840 study eyes with DMO were randomised to either focal or grid laser photocoagulation $(n=330), 1$ mg TA $(n=256)$ or 4 mg TA $(n=254)$. At year three, the mean change in the visual acuity from baseline was +5 letters in the laser group and 0 letters in both the TA groups. For the three two-group comparisons, mean difference adjusted for baseline visual acuity and prior macular photocoagulation and $95 \%$ confidence interval $(\mathrm{Cl})$ were as follows: $+5.6(95 \% \mathrm{Cl},+0.8$ to +10.4$)$ for laser versus $1 \mathrm{mg}$ TA groups; +4.7 (95\% Cl, 0.0 to +9.5) for laser versus $4 \mathrm{mg}$ TA groups; and $-0.8(95 \% \mathrm{Cl},-6.0$ to +4.3$)$ for $1 \mathrm{mg}$ TA versus $4 \mathrm{mg}$ TA groups. A worsening of visual acuity of three or more lines occurred in $8 \%, 17 \%$ and $16 \%$ of eyes, respectively, and an improvement in visual acuity by three or more lines occurred in $26 \%, 20 \%$ and $21 \%$ of eyes, respectively. Mean $( \pm \mathrm{SD})$ reductions in central macular thickness were $175 \pm 149 \mu \mathrm{m}$ in the laser group, $124 \pm 184 \mu \mathrm{m}$ in the $1 \mathrm{mg}$ TA group and $126 \pm 159 \mu \mathrm{m}$ in the $4 \mathrm{mg}$ TA group. The mean number of treatments at the end of the follow-up was 3.1 for the laser group, 4.2 for the $1 \mathrm{mg}$ and 4.1 for the $4 \mathrm{mg}$ TA groups. At the four-month visit, mean visual acuity improvement was higher in the $4 \mathrm{mg}$ TA group $(4 \pm 12$ letters improvement) than in either the laser group $(0 \pm 13$ letters change) or the $1 \mathrm{mg}$ TA group ( $0 \pm 13$ letters change). By 12 months, there were no significant differences among groups in mean visual acuity. Therefore, in this study, photocoagulation was shown to be more effective over time and had fewer side effects than TA. This was considered in support of focal/grid photocoagulation. However, it must be noted that during the 36 months of follow-up, patients received only four treatments with intravitreal $T A$, which is a low reinjection rate based on common experience and pharmacokinetic (PK) data. Recently, a new, large, randomised DRCR.net study investigated the efficacy of intravitreal TA in combination with laser photocoagulation in comparison with intravitreal ranibizumab with prompt or deferred laser photocoagulation or laser photocoagulation alone. At two-year visit, compared with the sham + prompt laser group, the mean change in the visual acuity letter score from baseline was 3.7 letters greater in the ranibizumab + prompt laser group $(p=0.03), 5.8$ letters greater in the ranibizumab + deferred laser group $(p<0.01)$ and 1.5 letters worse in the TA + prompt laser group $(\mathrm{p}=0.35)$. A worsening of visual acuity of three or more lines occurred in $10 \%, 4 \%, 2 \%$ and $13 \%$ of eyes, respectively, and an improvement in visual acuity by three or more lines occurred in $18 \%, 29 \%, 28 \%$ and $22 \%$ of eyes, respectively. Compared with the sham + prompt laser group, the mean change in central macular thickness from baseline was $31 \mu \mathrm{m}$ worse in the ranibizumab + prompt laser group $(p=0.03), 28 \mu \mathrm{m}$ worse in the ranibizumab + deferred laser group $(p=0.01)$ and $10 \mu \mathrm{m}$ worse in the TA + prompt laser group $(p=0.37)$. These results showed that intravitreal ranibizumab with prompt or deferred laser is more effective than prompt laser alone or intravitreal TA combined with laser for the treatment of diabetic macular oedema involving the central macula. Among the eyes that were pseudophakic at baseline, the mean change in visual acuity letter score from baseline to the two-year visit was 1.6 letters greater in the TA + prompt laser group compared with the sham + prompt laser group and was similar to difference in outcomes between the ranibizumab + prompt laser group (+0.5 letters) and the ranibizumab + deferred laser group (+3.5 letters) compared with the sham + prompt laser group. Cataract surgery was required in $12 \%$ of phakic eyes in the sham + prompt laser and in the ranibizumab + prompt laser groups, in $13 \%$ of phakic eyes in the ranibizumab + deferred laser group and in $55 \%$ of patients of the TA + laser group. An intraocular pressure (IOP)-lowering medication was required in $5 \%$ of eyes in the sham + prompt laser and ranibizumab + prompt laser groups, in $3 \%$ of eyes in the ranibizumab + deferred laser group and in $28 \%$ of patients of the TA + laser group. ${ }^{31}$ Other studies demonstrated promising results of combination therapy with intravitreal injection of TA and laser photocoagulation for the treatment of proliferative diabetic retinopathy (PDR) with clinically significant macular oedema (CSMO). ${ }^{32-36}$ In a 12-month randomised clinical trial conducted by Maia et al., 44 eyes with PDR and CSMO were enrolled and randomised to treatment with combined $4 \mathrm{mg}$ of intravitreal TA and laser photocoagulation $(n=22)$ or to laser photocoagulation alone $(n=22)$. Mean best corrected visual acuity (BCVA) improved significantly 
$(p<0.001)$ in the TA and laser group compared with the laser alone group at all study follow-up visits. An improvement of two or more Early Treatment Diabetic Retinopathy Study (ETDRS) lines was observed in $63.1 \%$ and $10.5 \%$ of eyes, respectively $(p<0.001)$. A significant decrease in mean central macular thickness occurred in the TA and laser group when compared with the laser alone group at all study follow-up intervals $(p<0.001)$. At 12 months, mean $( \pm S D)$ reductions in central macular thickness were $123 \pm 68 \mu \mathrm{m}$ and $65 \pm 51 \mu \mathrm{m}$, respectively $(p<0.001) .{ }^{37}$ Several other studies reported favourable results of intravitreal TA in refractory $\mathrm{DMO}^{23,38-40}$ In a six-month prospective, placebo-controlled, randomised clinical trial conducted by Jonas et al., 40 eyes with persistent DMO were enrolled and randomised to treatment with $20 \mathrm{mg}$ TA $(n=28)$ or to placebo injection $(n=12)$. Visual acuity increased significantly $(p<0.001)$ in the TA group by 3.4 ETDRS lines. In the placebo group, visual acuity did not change significantly $(p=0.07)$ during the six months. At the end of follow-up period, $48 \%$ in the TA group improved by at least two ETDRS lines compared with $0 \%$ eyes in the placebo group. ${ }^{23}$ Recently, Gillies et al. reported the longest-term data available concerning the outcomes of intravitreal injection of TA. This was a five-year prospective, double-masked, randomised clinical trial of $4 \mathrm{mg}$ dose of preservative-free intravitreal TA in comparison with placebo. In this study, 67 study eyes with refractory DMO were randomised to receive $4 \mathrm{mg}$ TA $(n=33)$ or placebo $(n=34)$. At five years, an improvement in visual acuity of three or more lines occurred in $42 \%$ of eyes in the TA group and $32 \%$ of eyes in the placebo group $(p=0.4)$. A worsening of visual acuity by three or more lines occurred in $18 \%$ and $24 \%$ of eyes, respectively $(p=0.88)$. Mean $( \pm S D)$ reductions in central macular thickness were $100 \pm 79 \mu \mathrm{m}$ in the TA group and $184 \pm 29 \mu \mathrm{m}$ in the placebo group ( $p=0.45$ ). After five years the difference in visual acuity between the two groups was not statistically significant and there was no difference in mean central macular thickness reduction between two groups. ${ }^{39}$ Moreover, this study showed that, in the long term, a two-year delay in the beginning of intravitreal TA treatment did not seem to adversely affect outcomes in eyes affected with refractory DMO.

\section{Dosage}

The appropriate dose of intravitreal TA remains a subject of debate. Both Hauser et al. and Audren et al. showed that the use of a $4 \mathrm{mg}$ dose of intravitreal TA does not have enough advantages over the lower $1 \mathrm{mg}$ or $2 \mathrm{mg}$ dose.40,41 However, Lam et al. published a comparison between $4 \mathrm{mg}$ and $8 \mathrm{mg}$ doses and showed that the higher dose had a more sustained effect on both visual acuity and central macular thickness, although with a trend to more ocular complications. ${ }^{42}$ By using a dose of about $20 \mathrm{mg}$ of TA, the increase in visual acuity was most marked during the first three and six months after injection and was observable for a period of about six to nine months. Differently, by using a dose of $4 \mathrm{mg}$, the duration in the reduction of macular thickness as measured by optical coherence tomography (OCT) was less than six months. ${ }^{43}$

\section{Other Routes of Administration}

While intravitreal TA administration has been shown useful to reduce the macular oedema and to improve or at least stabilise visual acuity, these effects are often transient and associated with several adverse events. Therefore, emerging pharmacological approaches are being evaluated for the treatment of DMO, including extraocular delivery routes and intravitreal steroid-releasing implants. Geroski et al. reported that therapeutic doses of TA could reach the posterior segment via transscleral absorption with periocular administration. ${ }^{44}$
Thus, other routes of TA administration, such as sub-conjunctival, sub-Tenon and posterior juxtascleral infusions, have been considered. The commonly reported advantages of periocular administration of TA versus intravitreal injection include a lower risk of IOP elevation and endophthalmitis. However, peribulbar injections of TA seem to result in lower morphological and functional outcomes as compared with those reported with the use of intravitreal TA. ${ }^{45-50}$ Recently, a 12-month interventional case report demonstrated that posterior juxtascleral infusion of a viscoelastic formulation of TA is an effective treatment for diffuse DMO unresponsive to laser photocoagulation. ${ }^{51}$ Morphological results indicated that macular thickness changed significantly $(p<0.001)$ after 12 months of follow-up. Serial comparison between baseline and post-treatment values demonstrated that the decrease in the mean central foveal thickness (CFT) was significant at each follow-up time $(p<0.0005)$. One week after TA infusion, mean reduction in CFT was $134 \mu \mathrm{m}$ and the effect duration reaches approximately six-nine months. One infusion only was given in $54.5 \%$ of eyes. A decrease in macular thickening of $50 \%$ or more was present in half of the eyes at the end of the 12 months of follow-up. Moreover, BCVA results changed significantly $(p<0.006)$. Serial comparison between baseline and post-treatment values demonstrated that the improvement in mean BCVA was significant one, three, nine and 12 months after treatment $(p<0.008)$. At the end of the study, the mean improvement in BCVA was 0.15 IogMAR. In $63 \%$ of eyes, the improvement was at least one ETDRS line, and in $27.3 \%$ cases it was greater than three ETDRS lines. A BCVA reduction of more than three lines was noted in four cases during the follow-up time. To provide long-term drug delivery to the macular region and to limit the frequency of repeated intraocular TA injections, several intravitreal steroid-releasing therapies are being proposed for the treatment of DMO. A controlled-release microsphere system for TA has been recently reported. A single intravitreal injection of $1 \mathrm{mg}$ TA in a controlled-release poly(lactide-co-glycolide) (PLGA) microsphere system (intravitreal bioerudivel sustained-release triamcinolone microspheres system; RETAAC system) has been compared with a single intravitreal injection of $4 \mathrm{mg}$ TA in patients with DMO unresponsive to laser photocoagulation. Both the safety and the anatomic and functional outcomes were evaluated. RETAAC-treated eyes showed marked decrease of retinal thickness as well as improved visual acuity after 12 months of follow-up. This study demonstrated a superior long-term pharmacologic performance compared with TA-injected eyes. No drug-or procedure-related side effects were observed in this study. ${ }^{52}$ Another promising approach seems to be represented by Verisome ${ }^{\circledR}$ technology. Verisome is a sustained-release drug delivery system that can be injected into the eye as a liquid via a standard 30-gauge needle. The biodegradable vehicle provides controlled, extended drug release over a titratable period of up to one year. The liquid-gel formulation was designed to deliver TA for up to one year via a single intravitreal injection to treat patients with macular oedema associated with retinal vein occlusion. ${ }^{53}$ The results of the clinical trial confirmed the expected safety and efficacy characteristics and the controlled-release attributes of the technology. Recently, Verisome technology has been proposed to treat patients affected with DMO. ${ }^{54}$ Moreover, new biodegradable and non-biodegradable steroid delivery systems are being evaluated for long-term efficacy in chronic diseases, such as DMO. These include dexamethasone (Ozurdex ${ }^{\circledR}$, Allergan Inc., Irvine, CA) and fluocinolone acetonide implants (Iluvien ${ }^{\circledR}$, Alimera Sciences, Alpharetta, GA), both of which have an approximately five-fold increase in corticosteroid potency. ${ }^{55,56}$ 


\section{Safety Profile}

The safety evaluation of the administration of intravitreal TA has been investigated by several randomised controlled clinical trials. Potential complications of intravitreal steroid treatment are divided into steroid-related and injection-related adverse effects. Steroid-related side effects most commonly include the increase of IOP and cataract formation. Injection-related side effects include endophthalmitis, pseudoendophthalmitis, rhegmatogenous retinal detachment and toxic effects.

\section{Post-injection Infectious Endophthalmitis}

Infectious endophthalmitis is one of the most serious complications of intravitreal injection of TA, with the reported risk per injection ranging from $0.1 \%$ to $1.6 \%{ }^{57}$ Many studies suggest that this relatively high rate of infectious endophthalmitis may be attributed to the techniques used for injection. If the injection is performed under sterile conditions, the risk of an infection may be lower. ${ }^{58-65}$ Patients with infectious endophthalmitis after intravitreal TA usually present without pain, which is uncommon for infectious endophthalmitis in eyes without intraocular steroids. ${ }^{66}$

\section{Post-injection Pseudoendophthalmitis}

Several studies have described non-infectious endophthalmitis after intravitreal injection of TA. ${ }^{67,68}$ Post-injection pseudoendophthalmitis is present if TA crystals are washed from the vitreous cavity into the anterior chamber and settle down in the inferior anterior chamber angle mimicking hypopyon. According to reports, this complication occurs in $0.2-6.7 \%$ of eyes following treatment. TA crystals in the anterior chamber usually disappear spontaneously and may not need to be removed. There have been no reports so far showing corneal endothelial damage or damage to the trabecular meshwork by the crystals. ${ }^{69}$

\section{Steroid-induced Ocular Hypertension}

A number of reports have described IOP elevation as the most common adverse event of intravitreal TA. ${ }^{70-82}$ Mild to moderate IOP elevation was seen in $28-42 \%$ of patients, typically within the first three months following injection. This condition is usually controlled with topical agents alone. About $1 \%$ of patients require surgical treatment. Selective laser trabeculoplasty (SLT) is a treatment alternative or adjunct to medical therapy. Comparing studies using different doses of TA for intravitreal injection suggests that the risk of IOP rise appears to be higher due to the prolonged elevated concentrations that are achieved intraocularly. If further studies confirm the assumption that the frequency of secondary ocular hypertension after an intravitreal TA injection may not markedly depend on the dose used, one may assume that even relatively low TA doses are already high enough to occupy all steroid receptors. Some authors suggest that pre-medication with topical steroids may be useful to identify possible steroid responders and excluding them from intravitreal TA treatment may lower the incidence of IOP elevation. ${ }^{83-85}$

\section{Steroid-induced Cataract}

Steroid-induced cataract is a common side effect of intravitreal TA. ${ }^{77,86-88}$ A recent study reported that, in the elderly population, intravitreal high-dose injections of TA led to clinically significant cataract with eventual cataract surgery in about $15-20 \%$ of eyes within about one year of the intravitreal injection. ${ }^{86}$ Gillies et al. concluded that eyes with an elevation of IOP after intravitreal TA have a very high risk of rapidly experiencing posterior subcapsular lens opacification. ${ }^{87}$ This strong association suggests a similar mechanism responsible for the development of steroid-induced posterior subcapsular cataract and for the elevation of IOP. A study suggested that a single intravitreal TA induces posterior subcapsular cataract development, whereas multiple injections result in all-layer cataract progression..$^{88}$

\section{Rhegmatogenous Retinal Detachment}

A potential complication of the intravitreal TA injection may be a rhegmatogenous retinal detachment. ${ }^{89}$ Triamcinolone acetonide, injected into the vitreous cavity, leads to a change in the structure of the vitreous body and the abnormal vitreous may exert traction on the retina. In particular, this is supposed for the inferior midperipheral area of the vitreo-retinal interface where the TA crystals remain in the preretinal vitreal cortex; for superior midperipheral and peripheral regions where a vitreous traction might be induced by the weight of the TA crystals settled at six o'clock; and for the far periphery of the fundus where the vitreous, incarcerated into the injection site, causes retinal traction.

\section{Toxic Effects}

Previous studies in rabbits found that preservatives in the vehicle for suspension of crystalline steroids, rather than steroid itself, could be toxic to the rabbit retina and lens and that the vehicle is not totally responsible for the toxicity, but may initiate TA-dependent toxicity. ${ }^{90,91}$ Direct toxic effects of TA on the retina and optic nerve have not yet been observed, independently of the dose used. ${ }^{92}$ TA has been shown to be toxic to retinal pigment epithelial cells in vitro, ${ }^{93}$ whereas ex vivo $^{94}$ and in vivo ${ }^{95}$ studies have failed to show any significant toxicity to the retina. Because TA is a heavy depot formulated suspension, it settles in the inferior vitreous cavity. Whereas there is certainly distribution of the drug throughout the vitreous cavity due to diffusion and constant eye movements, it is possible that the drug does not distribute equally in the vitreous cavity and that the concentration of the drug at the macula is different (presumably lower) than in the inferior retinal periphery. ${ }^{96}$ Yeung et al. reported a possible cytotoxic effect of TA, causing a significant reduction in cell numbers throughout the whole range of concentrations when retinal pigment epithelium cells were exposed to it for more than one day. ${ }^{97}$ compared with dexamethasone and hydrocortisone, TA showed the higher relative toxicity.

Safety of Intravitreal TA Including High-dose Reinjections In a case series study, Gilles et al. showed that side effects or complications may not occur more frequently after reinjections of TA than after a primary intravitreal high-dose injection. ${ }^{81}$ Moreover, the intravitreal high-dose reinjections may be tolerated by eyes within a mean follow-up of about 21 months after the first injection, or about 10 months after the last injection and the increase in IOP may not be more marked after a repeated injection than after the first injection.

\section{Systemic Safety}

In the randomised study from DRCR.net comparing laser photocoagulation with ranibizumab in combination with laser and intravitreal TA associated with laser, no evidence suggests that the administration of TA is associated with an increased risk of systemic adverse events, including stroke or cardiac events. Two-year incidence of non-fatal myocardial infarction was $3 \%$ in the laser alone group, $1 \%$ in the ranibizumab-laser group and $3 \%$ in the TA-laser group. Any cardiovascular event, as defined by the Antiplatelet Trialists' 
Collaboration (ATC), occurred in $12 \%$ of the laser alone group, $5 \%$ of the ranibizumab-laser group and $6 \%$ of the TA-laser group. ${ }^{31}$

\section{Conclusions}

DMO remains the leading cause of visual impairment in the working-age population. Emerging pharmacological approaches are being evaluated to treat DMO unresponsive to laser therapy. Many retinal physicians have begun to routinely inject TA as a promising option for the treatment of refractory DMO, although in these cases the intravitreal administration of TA is not FDA approved and has been mostly used off-label. Intravitreal TA has been found to significantly increase the visual acuity and decrease central macular thickness in short-term follow-up. Despite a very favourable systemic safety profile, a significant proportion of patients experience a rise in IOP and cataract development following intravitreal TA injections. The incidence of severe ocular adverse events such as infectious endophthalmitis, pseudoendophthalmitis, retinal toxicity and rhegmatogenous retinal detachment remains on the low side. Recently, a combined strategy of intravitreal injection of TA and laser photocoagulation has been evaluated for the treatment of DMO. ${ }^{31}$ In this study laser photocoagulation appeared safer and more effective than the combination of intravitreal injection of TA and laser treatment. However, when considering patients that were pseudophakic at baseline, TA in combination with laser resulted in better visual outcomes than laser alone. The results of the combination of TA and laser were comparable to those obtained with the combination of laser and ranibizumab in this subgroup of patients after two years of follow-up. ${ }^{31}$ The rationale for combining laser photocoagulation and intravitreal TA lies in their synergistic mechanism of action and may offer the chance to reduce the number of intravitreal injections required and so decrease the rate of drug- and injection-related adverse events. However, several vision-threatening side effects have been reported as a result of thermal damage caused by laser procedure. ${ }^{98-100}$ In recent years advances in laser therapy of retinal diseases have been directed at reducing the unnecessary disruptive effect that laser photocoagulation produces in retinal tissues. Several studies have shown the efficacy of sub-threshold laser photocoagulation in treating DMO, producing fewer side effects than conventional laser treatment. ${ }^{101-105}$ Combining intravitreal TA and sub-threshold laser photocoagulation may be a promising option to obtain good and durable visual outcomes while reducing the side effects correlated to either the laser procedure or the drug.

Many questions still remain unanswered concerning the optimal dose of TA for intravitreal use and the side-effect profiles of various commercially available formulations of TA with and without preservatives. Thus, an optimal balance between efficacy and safety profile has yet to be completely determined. Novel steroid implants and anti-VEGF drugs are being evaluated alone or in combination as promising options in the emerging armamentarium for the treatment of DMO.
1. Machemer R, Sugita G, Tano $Y$, Treatment of intraocular proliferations with intravitreal steroids, Trans Am Ophthalmo Proliferations with int $1979 ; 77: 171-80$.

2. Abelson MB, Butrus $S$, Corticosteroids in ophthalmic practice. In: Abelson MB, Neufeld AH, Topping TM, eds, Principles and Practice of Ophthalmology, Philadelphia, PA: WB Saunders, 1994:1014

3. Scholes GN, O'Brien WJ, Abrams GW, et al., Clearance of triamcinolone from vitreous, Arch Ophthalmol, 1985;103:1567-9.

4. Beer PM, Bakri SJ, Singh RJ, et al., Intraocular concentration and pharmacokinetics of triamcinolone acetonide after a single intravitreal injection, Ophthalmology, 2003;110:681-6. single intravitreal injection, Ophthalmology, 2003;110:681-6.
Audren F, Tod M, Massin P, et al., Pharmacokinetic-

5. Audren $F$, Tod $M$, Massin $P$, et al., Pharmacokinetic-
pharmacodynamic modeling of the effect of triamcinolon pharmacodynamic modeling of the effect of triamcinolo
acetonide on central macular thickness in patients with diabetic macular edema, Invest Ophthalmol Vis Sci, 2004;45:3435-41.

6. Inoue $\mathrm{M}$, Takeda $\mathrm{K}$, Morita $\mathrm{K}$, et al., Vitreous concentrations of triamcinolone acetonide in human eyes after intravitreal or subtenon injection, Am J Ophthalmol, 2004;138:1046-8.

7. Yilmaz T, Weaver $C D$, Gallagher MJ, et al., Intravitreal triamcinolone acetonide injection for treatment of refractory diabetic macular edema: a systematic review, Ophthalmology, 2009;116:902-11.

8. Juergens UR, Jager F, Darlath W, et al., Comparison of in vitro-activity of commonly used topical glucocorticoids on cytokine- and phospholipase inhibition, Eur J Med Res, 2004;31:383-90

9. Tong JP, Lam DS, Chan WM, et al., Effects of triamcinolone on the expression of VEGF and PEDF in human retinal pigment epithelial and human umbilical vein endothelial cells, Mol Vis, 2006;12:1490-5.

10. Smit-McBride Z, Moditahedi SP, Cessna CT, et al., In Vivo Gene Expression Profiling of Retina Post-Intravitreal Injections of Dexamethasone and Triamcinolone at Clinically Relevant Time Points for Patient Care, Ophthalmol Vis Sci, 2011;10:7084.

11. Tsaprouni $L G$, Ito $K$, Punchard $N$, et al., Triamcinolone acetonide and dexamethasome suppress TNF-alpha-induced histone $\mathrm{H} 4$ acetylation on lysine residues 8 and 12 in
mononuclear cells, Ann N Y Acad Sci, 2002;973:481-3.

12. Mizuno S, Nishiwaki A, Morita $H$, et al., Effects of periocular administration of triamcinolone acetonide on leukocyteendothelium interactions in the ischemic retina, Invest endothelium interactions in the ische
ophthalmol Vis Sci, 2007;48:2831-6.

13. Tamura H, Miyamoto K, Kiryu J, et al., Intravitreal injection of corticosteroid attenuates leukostasis and vascular leakage in experimental diabetic retina, Invest Ophthalmol Vis Sci, 2005;46:1440-4

14. Sutter FK, Simpson JM, Gillies MC, Intravitreal triamcinolone for diabetic macular edema that persists after laser treatment: three-month efficacy and safety results of a prospective, randomized, double-masked, placebo-controlled clinical trial, Ophthalmology, 2004;111:2044-9.
15. Ciardella AP, Klancnik J, Schiff W, et al., Intravitreal triamcinolone for the treatment of refractory diabetic macular oedema with hard exudates: an optical coherence tomography study, Br J Ophthalmol, 2004;88:1131-6.

16. Micelli Ferrari T, Sborgia L, Furino C, et al., Intravitreal triamcinolone acetonide: valuation of retinal thickness changes measured by optical coherence tomography in diffuse diabet macular edema, Eur J Ophthalmol, 2004;14:321-4.

17. Lee WF, Yang $\mathrm{CM}$, Intravitreal triamcinolone injection for macular edema secondary to increased retinal vascular permeability, I Formos Med Assoc, 2004;103:692-700.

18. Karacorlu M, Ozdemir H, Karacorlu S, et al., Intravitrea triamcinolone as a primary therapy in diabetic macular oedema, Eye, 2005;19:382-6.

19. Bhagat N, Ruben A, Tutela A, et al., Diabetic Macular Edema: pathogenesis and Treatment, Surv Opthalmol, 2009;54:1-32

20. Audren F, Erginay A, Haouchine B, et al., Intravitreal triamcinolone acetonide for diffuse diabetic macular oedema: 6-month results of a prospective controlled trial, Acta Ophthalmol Scand, 2006:84:624-30.

21. Avitabile $T$, Longo $A$, Reibaldi A, Intravitreal triamcinolone compared with macular laser grid photocoagulation for the treatment of cystoid macular edema, Am J Ophthalmol, 2005:140:695-702

22. Gillies MC, Sutter FK, Simpson JM, et al., Intravitreal triamcinolone for refractory diabetic macular edema: twoyear results of a double-masked, placebo-controlled randomized clinical trial, Ophthalmology, 2006;113:1533-8.

23. Jonas JB, Kamppeter BA, Harder B, et al., Intravitreal triamcinolone acetonide for diabetic macular edema: a prospective, randomized study, I Ocul Pharmacol Ther, 2006;22:200-7.

24. Early Treatment Diabetic retinopathy Study Reasearch Group, Photocoagulation for diabetic macular edema. Early Treatment Diabetic retinopathy Study report number 1, Arch Ophthalmol, 1985;103:1796-806

25. Early Treatment Diabetic retinopathy Study Research Group Treatment techniques and clinical guidelines for photocoagulation of diabetic macular edema. Early Treatment Diabetic retinopathy Study report number 2 Ophthalmology, 1987;94:761-74.

26. Lee CM, Olk RJ, Modified grid laser photocoagulation for diffuse diabetic macular edema. Long-term visual results, Ophthalmology, 1991;98:1594-602.

27. Veritti $D$, Perissin $L$, Zorzet $S$, et al., The effect of triamcinolone acetonide, sodium hyaluronate, and chondroitin sulfate on human endothelial cells: an in vitro study, Eur J Ophthalmol, 2010;21:75-9.

28. Chang LK, Gomes NL, Zhou J, et al, Physical properties of commercially available formulations of triamcinolone acetonide, Br J Ophthalmol, 2009;93:1265-6.

29. Kupperman DB, Differentiating steroid delivery systems for macular edema, John Hopkins Advanced Studies in Ophthalmology, 2010;2:35-41.
30. Diabetic Retinopathy Clinical Research Network, A randomized trial comparing intravitreal triamcinolone acetonide and focal/grid photocoagulation for diabetic macular edema, Ophthalmology, 2008;115:1447-9.

31. Diabetic Retinopathy Clinical Research Network, Randomized trial evaluating ranibizumab plus prompt or deferred laser or triamcinolone plus prompt laser for diabetic macular edema, Ophthalmology, 2010;117:1064-77.

32. Choi KS, Chung JK, Lim SH, Laser photocoagulation combined with intravitreal triamcinolone acetonide injection in proliferative diabetic retinopathy with macular edema, Korean J Ophthalmol, 2007;21:11-7.

33. Kaderli B, Avci R, Gelisken O, et al., Intravitreal triamcinolone as an adjunct in the treatment of concomitant proliferative diabetic retinopathy and diffuse diabetic macular oedema. Combined IVTA and laser treatment for PDR with CSMO, Int ophthalmol, 2007;26:207-14

34. Zacks DN, Johnson MW, Combined intravitreal injection of triamcinolone acetonide and panretinal photocoagulation for concomitant diabetic macular edema and proliferative diabetic retinopathy, Retina, 2005;25:135-40.

35. Zein WM, Noureddin BN, Jurdi FA, et al., Panretinal photocoagulation and intravitreal triamcinolone acetonide for the management of proliferative diabetic retinopathy with macular edema, Retina, 2006;26:137-42.

36. Bandello F, Polito A, Pognuz DR, et al., Triamcinolone as adjunctive treatment to laser panretinal photocoagulation for proliferative diabetic retinopathy, Arch Ophthalmol 2006; $124: 643-50$

37. Maia OO, Takahashi BS, Costa RA, Combined Laser and Intravitreal Triamcinolone for Proliferative Diabetic Retinopathy and Macular Edema: One-year Results of a Randomized Clinical Trial, Am J Ophthalmol, 2009;147:291-7.

38. Kim JE, Pollack JS, Miller DG, et al., ISIS-DME: a prospective randomized, dose-escalation intravitreal steroid injection study for refractory diabetic macular edema, Retina, 2008;28:735-40.

39. Gillies MC, Simpson JM, Gaston C, et al., Five-year results of a randomized trial with open-label extension of triamcinolone acetonide for refractory diabetic macular edema, Ophthalmology, 2009:116:2182-7.

40. Audren F, Erginay A, Haouchine B, et al., Intravitreal triamcinolone acetonide for diffuse diabetic macular oedema: 6-month results of a prospective controlled trial, Acta Ophthalmol scand, 2006;84:624-30.

41. Hauser D, Bukelman A, Pokroy R, et al., Intravitreal triamcinolone for diabetic macular edema: comparison of 1 2, and $4 \mathrm{mg}$, Retina, 2008;28:825-30

42. Lam DS, Chan CK, Mohamed S, et al., A prospective randomised trial of different doses of intravitreal triamcinolone for diabetic macular oedema, Br I Ophthalmol, 2007;91:199-203.

43. Massin P, Audren F, Haouchine B, et al., Intravitrea triamcinolone acetonide for diabetic diffuse macular edema: 
preliminary results of a prospective controlled trial, Ophthalmology, 2004;111:218-24

44. Geroski DH, Edelhauser HF, Transscleral drug delivery for posterior segment disease, Adv Drug Deliv Rev, 2001:52:37-48.

45. Bonini-Filho MA, Jorge R, Barbosa JC, et al., Intravitreal injection versus sub-Tenon's infusion of triamcinolone acetonide for refractory diabetic macular edema: a randomized clinical trial, refractory diabetic macular edema: a rand

46. Cardillo JA, Melo LA, Jr., Costa RA, et al., Comparison of intravitreal versus posterior sub-Tenon's capsule injection of triamcinolone acetonide for diffuse diabetic macular edema Ophthalmology, 2005;112:1557-63.

47. Ozdek S, Bahceci UA, Gurelik G, et al., Posterior subtenon and intravitreal triamcinolone acetonide for diabetic macular edema, J Diabetes Complications, 2006;20:246-51.

48. Choi YJ, Oh IK, Oh JR, et al., Intravitreal versus posterior subtenon injection of triamcinolone acetonide for diabetic macular edema, Korean I Ophthalmol, 2006:20:205-9.

49. Bakri SJ, Kaiser PK, Posterior subtenon triamcinolone acetonide for refractory diabetic macular edema, Am J Ophthalmol, 2005;139:290-4.

50. Cellini M, Pazzaglia A, Zamparini E, et al., Intravitreal vs. subtenon triamcinolone acetonide for the treatment of diabetic cystoid macular edema, BMC Ophthalmol, 2008:8:5.

51. Veritti D, Lanzetta P, Perissin L, et al., Posterior juxtascleral infusion of modified triamcinolone acetonide formulation for refractory diabetic macular edema: one-year follow-up, Invest Ophthalmol Vis Sci, 2009;50:2391-7.

52. Cardillo JA, Souza-Filho AA, Oliveira AG, Intravitreal bioerudivel sustained-release triamcinolone microspheres system (RETAAC). Preliminary report of its potential usefulness for the treatment of diabetic macular edema, Arch SOC ESP Oftalmol, 2006;81:675-82.

53. Lim Jl, Hung D, Fung AE, et al., One-year results of a phase study evaluating the safety and evidence of efficacy of a single intravitreal injection of the Verisome ${ }^{\mathrm{TM}}$ liquid drug delivery system for sustained release of low-dose triamcinolone (IBI-20089) in eyes with cystoid macular triamcinolone (IBI-20089) in eyes with cystoid macular edema. Paper presented at: 82nd Annual Meeting of the
Association for Research in Vision and Ophthalmology; May 2-6, 2010; Fort Lauderdale, FL.

54. Fung $A E$, One-year safety and efficacy of an injectable, sustained-delivery, liquid steroid for treatment of macular edema due to retinal vein occlusion. Paper presented at: Angiogenesis 2010; February 20, 2010; Miami, FL.

55. Kuppermann BD, Blumenkranz MS, Haller JS, et al., Randomized, controlled study of a novel intravitreous dexamethasone drug delivery system in patients with persistent macular edema, Arch Ophthalmol, 2007;125:309-17.

56. Pearson P, Comstock T, Ip M, et al., Fluocinolone acetonide intravitreal implant for diabetic macular edema: 3-year multicenter, randomized, controlled, clinical trial, Ophthalmology, 2011;118:1580-7

57. Scott IU, Flynn HW, Reducing the risk of endophthalmitis following intravitreal injections, Retina, 2007:27:10-2.

58. Benz MS, Murray TG, Dubovy SR, et al., Endophthalmitis caused by Mycobacterium chelonae abscessus after intravitreal injection of triamcinolone, Arch Ophthalmol 2003;121:271-3.

59. Jonas JB, Bleyl U, Morphallaxia-like ocular histology after intravitreal triamcinolone acetonide, Br J Ophthalmol, 2004;88:839-40

60. Jonas JB, Kreissig I, Degenring RF, Endophthalmitis afte intravitreal injection of triamcinolone acetonide, Arch ophthalmol, 2003;121:1663-4

61. Jonas JB, Kreissig I, Spandau UH, et al., Infectious and noninfectious endophthalmitis after intravitreal high-dosage triamcinolone acetonide, Am J Ophthalmol, 2006:141:579-80.

62. Kreissig I, Degenring RF, Jonas JB, Intravitreal triamcinolone acetonide. Complication of infectious and sterile endophthalmitis, Ophthalmologe, 2006;103:30-4

63. Moshfeghi DM, Kaiser PK, Scott IU, et al., Acute endophthalmitis following intravitreal triamcinolone acetonide iniection, Am J Ophthalmol, 2003:136:791-6.

64. Parke DW, Intravitreal triamcinolone and endophthalmitis, Am J Ophthalmol, 2003;136:918-9.

65. Westfall AC, Osborn A, Kuhl D, et al., Acute endophthalmitis incidence: intravitreal triamcinolone, Arch Ophthalmol, 2005;123:1075-7

66. Nelson ML, Tennant MT, Sivalingam A, et al., Infectious and presumed noninfectious endophthalmitis after intravitrea triamcinolone acetonide injection, Retina, 2003:23:686-91.

67. Sutter FK, Gillies MC, Pseudo-endophthalmitis after intravitreal injection of triamcinolone, Br I Ophthalmol 2003;87:972-4.

68. Moshfeghi AA, Scott IU, Flynn HW, et al., Pseudohypopyon after intravitreal triamcinolone acetonide injection for cystoid macular edema, Am I Ophthalmol, 2004;138:489-92.

69. Roth DB, Chieh J, Spirn MJ, et al., Noninfectious endophthalmitis associated with intravitreal triamcinolone injection, Arch Ophthalmol, 2003;121:1279-82.

70. Agrawal S, Agrawal J, Agrawal TP, Vitrectomy as a treatment for elevated intraocular pressure following intravitreal injection of triamcinolone acetonide, Am I Ophthalmol, 2004;138:679-80

71. Viola F, Morescalchi F, Staurenghi G, Argon laser trabeculoplasty for intractable glaucoma following intravitreal triamcinolone, Arch Ophthalmol, 2006:124:133-4.

72. Park HY, Yi K, Kim HK, Intraocular pressure elevation after intravitreal triamcinolone acetonide injection, Korean J Ophthalmol, 2005;19:122-7.

73. Bakri SJ, Beer PM, The effect of intravitreal triamcinolone acetonide on intraocular pressure, Ophthalmic Surg Lasers Imaging, 2003;34:386-90.

74. Bui Quoc E, Bodaghi B, Adam R, et al., Intraocular pressure elevation after subtenon injection of triamcinolone acetonid during uveitis, I Fr Ophtalmol, 2002:25:1048-56.

75. Chan CK, Fan DS, Chan WM, et al., Ocular-hypertensive response and corneal endothelial changes after intravitreal triamcinolone injections in Chinese subjects: a 6-month follow-up study, Eye, 2005;19:625-30

76. Detry-Morel M, Escarmelle A, Hermans I, Refractory ocular hypertension secondary to intravitreal injection of triamcinolone acetonide, Bull Soc Belge Ophtalmol, 2004;292:45-51.

77. Gillies MC, Kuzniarz M, Craig J, et al., Intravitrea triamcinolone-induced elevated intraocular pressure is associated with the development of posterior subcapsula cataract, Ophthalmology, 2005:112:139-43.

78. Gillies MC, Simpson JM, Billson FA, et al., safety of an intravitreal injection of triamcinolone: results from a randomized clinical trial, Arch Ophthalmol, 2004;122:336-40

79. Jonas JB, Degenring RF, Kreissig I, et al., Intraocular pressure elevation after intravitreal triamcinolone acetonide injection Ophthalmology, 2005;112:593-8.

80. Jonas JB, Kreissig I, Degenring R, Intraocular pressure after intravitreal injection of triamcinolone acetonide, $\mathrm{Br}\rfloor$ Ophthalmol, 2003;87:24-7.

81. Jonas JB, Degenring R, Kreissig I, et al., Safety of intravitreal high-dose reinjections of triamcinolone acetonide, $A m 」$ Ophthalmol, 2004;138:1054-5.

82. Jonas JB, Kreissig I, Degenring R, Secondary chronic openangle glaucoma after intravitreal triamcinolone acetonide Arch Ophthalmol, 2003;121:729-30.

83. Ozkiris A, Erkilic $\mathrm{K}$, Complications of intravitreal injection of triamcinolone acetonide, Can J ophthalmol, 2005:40:63-8.

84. Singh IP, Ahmad SI, Yeh D, et al., Early rapid rise in intraocular pressure after intravitreal triamcinolone acetonide injection, Am I Ophthalmol, 2004;138:286-7.
85. Smithen LM, Ober MD, Maranan L, et al., Intravitreal triamcinolone acetonide and intraocular pressure, Am J Ophthalmol, 2004;138:740-3.

86. Jonas JB, Degenring R, Vossmerbauemer U, et al., Frequency of cataract surgery after intravitreal injection of high-dosage triamcinolone acetonide, Eur J Ophthalmol, 2005; 15:462-4.

87. Gillies MC, Islam FM, Zhu M, et al., Efficacy and safety of multiple intravitreal triamcinolone injections for refractory diabetic macular oedema, Br J Ophthalmol, 2007;91:1323-6.

88. Cekic O, Chang S, Tseng JJ, et al., Cataract progression after intravitreal triamcinolone injection, Am J Ophthalmol, 2005;139:993-8.

89. Jaissle GB, Szurman P, Bartz-Schmidt KU, Ocular side effects and complications of intravitreal triamcinolone acetonide injection, Ophthalmologe, 2004;101:121-8.

90. Kai W, Yanrong J, Xiaoxin L, Vehicle of triamcinolone acetonide is associated with retinal toxicity and transient increase of lens density, Graefes Arch Clin Exp Ophthalmol 2006;244:1152-9.

91. Macky TA, Helmy D, El Shazly N, Retinal toxicity of triamcinolone's vehicle (benzyl alcohol): an electrophysiologic and electron microscopic study, Graefes Arch Clin Exp Ophthalmol, 2007;245:817-24.

92. Lang $\mathrm{Y}$, Zemel $\mathrm{E}$, Miller $\mathrm{B}$, et al., Retinal toxicity of intravitreal kenalog in albino rabbits, Retina, 2007;27:778-88.

93. Yeung $\mathrm{CK}$, Chan KP, Chan CK, et al., Cytotoxicity of triamcinolone on cultured human retinal pigment epithelial cells: comparison with dexamethasone and hydrocortisone Ipn J Ophthalmol, 2004;48:236-42.

94. Tokuda K, Tsukamoto T, Fujisawa S, et al., Evaluation of toxicity due to vital stains in isolated rat retinas, Acta Ophthalmol Scand, 2004;82:189-94.

95. Kivilcim M, Peyman GA, El-Dessouky ES, et al., Retinal toxicity of triamcinolone acetonide in silicone-filled eyes, Ophthalmic Surg Lasers, 2000;31:474-8.

96. Narayanan R, Mungcal JK, Kenney MC, et al., Toxicity of triamcinolone acetonide on retinal neurosensory and pigment epithelial cells, Invest Ophthalmol Vis Sci, 2006;47:722-8.

97. Yeung $\mathrm{CK}$, Chan KP, Chiang SW, et al., The toxic and stress responses of cultured human retinal pigment epithelium (ARPE19) and human glial cells (SVG) in the presence of triamcinolone, Invest Ophthalmol Vis Sci, 2003;44:5293-300

98. Schatz H, Madeira D, McDonald HR, et al., Progressive enlargement of laser scars following grid laser photocoagulation for diffuse diabetic macular edema, Arch Ophthalmol, 1991:109:1549-51.

99. Guyer DR, D'Amico DJ, Smith CW, Subretinal fibrosis after laser photocoagulation for diabetic macular edema, Am J Ophthalmol, 1992;113:652-6.

100. Prskavec FH, Fulmek R, Klemen C, et al., Changes in the visual field and dark adaptation following panretinal photocoagulation in diabetic retinopathy, Klin Monatsb Augenheilkd, 1986;189:385-7.

101. Stanga PE, Reck AC, Hamilton AM, Micropulse laser in the treatment of diabetic macular edema, Semin Ophthalmo 1999;14:210-3.

102. Laursen ML, Moeller F, Sander B, et al., Subthreshold micropulse diode laser treatment in diabetic macular oedema, Br J Ophthalmol, 2004:88:1173-9.

103. Luttrull JK, Musch DC, Mainster MA, Subthreshold diode micropulse photocoagulation for the treatment of clinically significant diabetic macular oedema, Br J Ophthalmol, 2005;89:74-80

104. Sivaprasad S, Sandhu R, Tandon A, et al., Subthreshold micropulse diode laser photocoagulation for clinically significant diabetic macular oedema: a three-year follow up, Clin Experiment Ophthalmol, 2007;35:640-4.

105. Lanzetta P, Polito A, Veritti D, Subthreshold laser, Ophthalmology, 2008;115:216 